effector cytokines are inhibited simultaneously may explain the strong antiinflammatory effect of abatacept in RA patients with high-titer ACPA and RF. References:

[1] Sokolove J, et al. Impact of baseline anti-cyclic citrullinated peptide-2 antibody concentration on efficacy outcomes following treatment with subcutaneous abatacept or adalimumab: 2-year results from the AMPLE trial. Ann Rheum Dis. 2016;75:709-14.

[2] Clavel C, et al Among human macrophages polarised to different phenotypes, the M-CSF-oriented cells present the highest pro-inflammatory response to the rheumatoid arthritis-specific immune complexes containing ACPA. Ann Rheum Dis. 2016;75:2184-2191.

[3] Bozec A, et al. T cell costimulation molecules CD80/86 inhibit osteoclast differentiation by inducing the IDO/tryptophan pathway. Sci TransI Med. 2014;6:235ra60.

Acknowledgements: This project was supported by an unrestricted research grant from BMS and the IMI project BTCure.

Disclosure of Interest: None declared

DOI: 10.1136/annrheumdis-2017-eular.4363

\section{SAT0202 EFFICACY AND SAFETY OF SARILUMAB MONOTHERAPY VERSUS ADALIMUMAB MONOTHERAPY IN PATIENTS WITH ACTIVE RHEUMATOID ARTHRITIS IN THE PHASE 3 MONARCH STUDY, INCLUDING SUBPOPULATIONS}

G.R. Burmester ${ }^{1}$, Y. Lin ${ }^{2}$, E.K. Mangan ${ }^{3}$, H. van Hoogstraten ${ }^{2}$, T. Kimura ${ }^{3}$, J.I. Vargas ${ }^{4}$, E.B. Lee ${ }^{5} .{ }^{1}$ Charité - University Medicine Berlin, Free University and Humboldt University Berlin, Berlin, Germany; ${ }^{2}$ Sanofi Genzyme,

Bridgewater; ${ }^{3}$ Regeneron Pharmaceuticals, Inc, Tarrytown, United States

${ }^{4}$ Quantum Research, Puerto Varas, Chile; ${ }^{5}$ Seoul National University College of Medicine, Seoul, Korea, Republic Of

Background: Efficacy and safety of sarilumab + csDMARDs in RA patients have been demonstrated.

Objectives: To compare sarilumab monotherapy with adalimumab monotherapy in the ITT population of adults with active RA from MONARCH (NCT02332590) and across predefined subgroups.

Methods: Adults ( $\mathrm{N}=369)$ intolerant of, inappropriate for, or inadequate responders (IR) to MTX (per investigator judgment) received SC sarilumab $200 \mathrm{mg}$ q2w or adalimumab $40 \mathrm{mg}$ q2w monotherapy. The primary endpoint was change from baseline in DAS28-ESR at wk 24. Consistency of treatment response (sarilumab vs adalimumab) for this endpoint was assessed in prespecified subpopulations.

Results: At wk 24, sarilumab was superior to adalimumab in change from baseline (BL) in DAS28-ESR $(-3.3$ vs $-2.2 ; P<0.0001)$. Sarilumab-treated patients achieved significantly higher rates of ACR20 response $(71.7 \%$ vs $58.4 \% ; P=0.0074)$ and greater improvement in HAQ-DI (-0.6 vs $-0.4 ; P=0.0037)$ and CDAI (-28.9 vs -25.2 ; nominal $P=0.0013$ ) vs adalimumab-treated patients. Extent of treatment effect with sarilumab vs adalimumab in change from baseline in DAS28-ESR at wk 24 was generally consistent $(P>0.05)$ across subgroups; significant treatment-bysubgroup interactions were observed for body mass index $(P=0.047)$ and baseline CRP $(P=0.006)$ (Figure). The magnitude of treatment effect for DAS28-ESR was greater in patients with lower BMI and higher baseline CRP. Treatment effect was generally similar for other efficacy endpoints assessed, including ACR20, HAQ-DI, and CDAl. Clinical and functional responses in RF+/ACPA+, RF+/ACPA-, RF/ACPA+, and RF-/ACPA- patients were similar to overall study results. Incidence of AEs was similar in both groups, including incidences of infections and serious infections. The most common AEs were neutropenia and injection site erythema (sarilumab) and headache and worsening of RA (adalimumab).

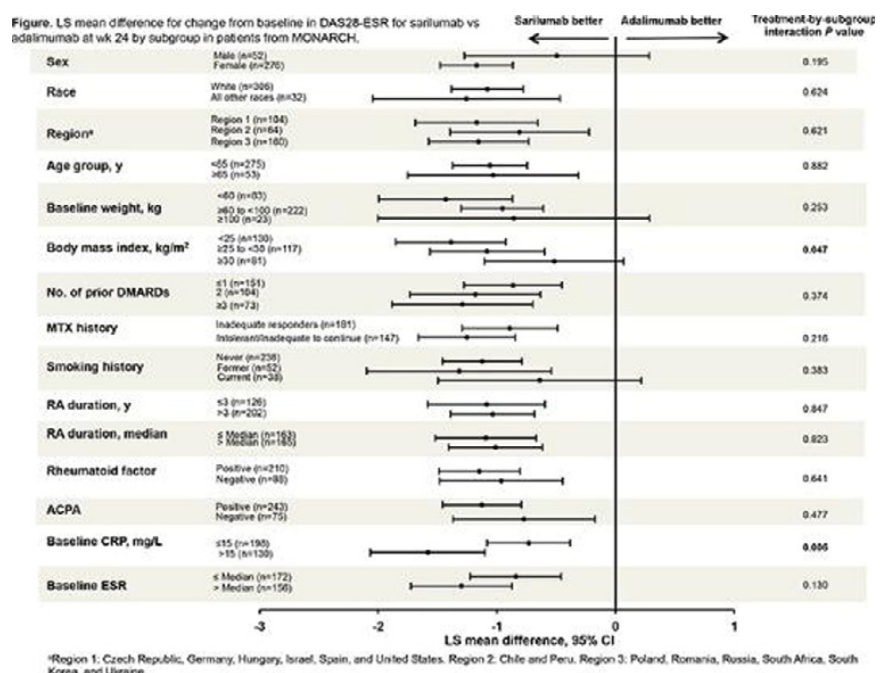

Conclusions: Sarilumab monotherapy demonstrated superiority to adalimumab monotherapy in the ITT population in change from baseline in DAS28-ESR. The extent of treatment effect with sarilumab vs adalimumab was generally consistent across subpopulations. Overall incidences of AEs and serious AEs and rates of infection and serious infection were similar between groups.

Acknowledgements: This study was sponsored by Sanofi Genzyme and Regeneron Pharmaceuticals, Inc. Medical writing support was provided by MedThink SciCom and funded by Sanofi Genzyme and Regeneron Pharmaceuticals, Inc. Disclosure of Interest: G. Burmester Grant/research support from: AbbVie, Bristol-Myers Squibb, Medlmmune, Merck, Pfizer, Roche, and UCB, Consultant for: AbbVie, Bristol-Myers Squibb, Medlmmune, Merck, Pfizer, Roche, and UCB, Speakers bureau: AbbVie, Bristol-Myers Squibb, Merck, Pfizer, Roche, and UCB, Y. Lin Shareholder of: Sanofi Genzyme, Employee of: Sanofi Genzyme, E. Mangan Shareholder of: Regeneron Pharmaceuticals, Inc, Employee of: Regeneron Pharmaceuticals, Inc, H. van Hoogstraten Shareholder of: Sanofi Genzyme, Employee of: Sanofi Genzyme, T. Kimura Shareholder of: Regeneron Pharmaceuticals, Inc, Employee of: Regeneron Pharmaceuticals, Inc, J. Vargas Grant/research support from: Roche, Bristol-Myers Squibb, and Pfizer, Speakers bureau: Bristol-Myers Squibb, E. Lee Consultant for: Pfizer

DOI: 10.1136/annrheumdis-2017-eular.4540

\section{SAT0203 SIGNIFICANCE OF EXTENSION OF TOCILIZUMAB INFUSION INTERVALS FROM 4 WEEKS TO 6 WEEKS IN RA PATIENTS WHO HAD SHOWN GOOD RESPONSE TO 4 WEEK INTERVALS}

H. Uda ${ }^{1}$, K. Shigematsu ${ }^{2}$, O. Saiki ${ }^{1,3} \cdot{ }^{1}$ Rheumatology; ${ }^{2}$ Orthopedics,

Higashiosaka City Medical Center, Higashiosaka; ${ }^{3}$ Internal Medicine, Shiraishi Hospital, Imabari, Japan

Background: A period of 4 weeks (w) has been recommended as tocilizumab (TCZ, $8 \mathrm{mg} / \mathrm{kg}$ ) infusions. However, we found that 5 or $6 \mathrm{w}$ intervals were also effective in more than $90 \%$ of RA patients with low disease activity (LDA) at $4 \mathrm{w}$ intervals (1).

Objectives: We conducted the study to investigate the significance of extension of intervals from $4 \mathrm{w}$ to $6 \mathrm{w}$. We compared, in the same patients, the clinical features such as diseases activity, major and minor side reactions between at $4 \mathrm{w}$ and at 6w. Moreover, we also considered the mechanisms.

Methods: This was a retrospective observational study. Among RA patients who had shown LDA with TCZ infusions at $4 w$ intervals, the patients who could extend the intervals from $4 \mathrm{w}$ to $6 \mathrm{w}$ with LDA for more than 2 years without changing the doses of oral medicines were enrolled. In the same patients, we compared the events of serious and common side reactions between at $4 \mathrm{w}$ and $6 \mathrm{w}$ intervals. We examined the course of the levels of total cholesterol (TCHO), triglyceride (TG), and platelet (PLT) counts. We also examined the levels of serum trough TCZ and IL-6.

Results: Among 120 patients who maintained LDA at $4 \mathrm{w}$ intervals, more than $60 \%$ of patients maintained LDA at $6 \mathrm{w}$ intervals. When we compared the disease activity of $6 w$-responders between at $4 w$ and $6 w$-intervals, all parameters reflecting the disease activities such as CRP and DAS28CRP score at $6 \mathrm{w}$ intervals were elevated significantly, but were still within LDA. At $4 w$ intervals, serious adverse events were occurred as much as 11 cases during 2 years. At $6 \mathrm{w}$ intervals, however, they were decreased to 3 cases only in the same period. The common adverse events such as general fatigue, nausea, and dizziness occurred frequently at $4 \mathrm{w}$ intervals in most of the patients. At $6 \mathrm{w}$ intervals, these common adverse events were decreased significantly. At $4 \mathrm{w}$ intervals, the levels of $\mathrm{TCHO}$ and $\mathrm{TG}$ were elevated significantly. At $5 \mathrm{w}$ and $6 \mathrm{w}$ intervals, however, they were decreased accordingly. At $6 \mathrm{w}$ intervals, they were within normal limits. In most of patients, the levels of PLT counts were decreased significantly at $4 \mathrm{w}$ intervals. At $5 \mathrm{w}$ and $6 \mathrm{w}$ intervals, however, they were increased gradually. When TCZ were infused at $4 \mathrm{w}$ intervals, the serum trough TCZ levels were around 10 $\mu \mathrm{g} / \mathrm{mL}$. In contrast, they became undetectable when extended to $5 \mathrm{w}$, and it is obvious that the trough TCZ levels of $6 \mathrm{w}$ were lower than $5 \mathrm{w}$. The levels of IL-6 were significantly high at $4 \mathrm{w}$-intervals, but the levels of IL-6 were decreased to less than $10 \mathrm{pg} / \mathrm{mL}$ at $5 \mathrm{w}$-intervals.

Conclusions: The present study provide evidence that more than half of RA patients who showed good response to TCZ infusions at $4 \mathrm{w}$ could extend the intervals to $6 \mathrm{w}$. By extension of intervals to $6 \mathrm{w}$, major and minor side reactions were reduced significantly, and the levels of TG, TCHO and PLT were also normalized with sustaining LDA, suggesting that the dose of TCZ $(8 \mathrm{mg} / \mathrm{kg})$ at $4 \mathrm{w}$ intervals might be excessive in some patients. Taken together, we should be careful for deciding the intervals of TCZ infusion in each patient.

References:

[1] Saiki O, Uda H. Successful extension of tocilizumab infusion intervals from 4 weeks to 6 or 5 weeks in $90 \%$ of RA patients with good response to 4 weeks intervals. Clin Exp Rheumatol (2017 in press).

Disclosure of Interest: None declared

DOI: 10.1136/annrheumdis-2017-eular.3602 